\title{
數種の低タングステンーモリブデンーバナジウム高速度鋼の 熱處理と切削耐久力に就いて。
}

(昭和 29 年 4 月本会請演大会にて講演)

\author{
小柴 定 雄*・永島 䀡 雄** \\ THE HEAT TREATMENT AND CUTTING-DURABILITY OF \\ VARIOUS LOW TUNGSTEN-MOLYBDEN-VANADIUM \\ HIGH SPEED SIEELS
}

Sadao Koshiba, Dr. Eng. and Sukeo Nagashima

\begin{abstract}
Sýnopsis:
Previously, one of the authors studied on the effects of each elements on the low tungsten-molybden-vanadium high speed stee] (Sadao Koshiba, Jnl. Japan Inst. of Metals, 16, 1652, No. 9, 511)

In this experiment, the authors studied the changes in their hardness and microsiructures bronght about by the heat treatments with the varions kinds of the moderately low tungstenmolybden-vanadium high speed steel containing $\mathrm{C} 0.7 \sim 1 \cdot 4 \%$, Or 3.5 4.5\%, W 4.0 8.0\%, Mo

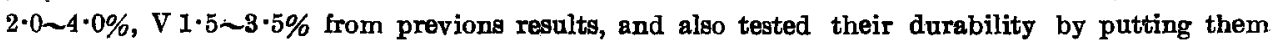
in actual service, and then made a comparison with the low-tungsten high speed steel and molybdenum high speed steel.

From thess experiments, the moderate compositions of low-W-Mo-V high speed steel were ascertained as follows:- $\mathrm{O} 0.8 \sim 1 \cdot 0 \%$, Or 4.0 4.5\%, W 4.0 5.0\%, Mo 3.0 4.0\%, V $2 \cdot 0 \sim 2 \cdot 5 \%$,

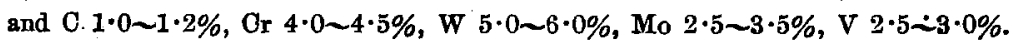

\section{I. 綪言}

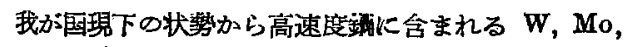
V よびCoな゙の重要金属資源を極力節隇すること は梪あて必要である。しかして同時に切削耐久力に和い てを逽色なく，むしろ假るすのを您求すること切なるる Фがむる.

著者の一人は先きに W 6\%, Mo $3 \%$ 或は W $3 \%$, Mo 6\% を合む低 W-Mo 系高速度銅比ついて各種元素 の影響を研究 ( ${ }^{122)}$, 叉更に $\mathrm{W} 6 \%, \mathrm{Mo} 2 \%, \mathrm{~V} 2 \%$ を

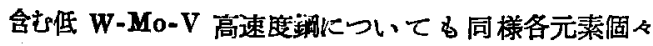
の影響を調へだす。

本研究に於ては上述の研究結果を基にして最も適当と

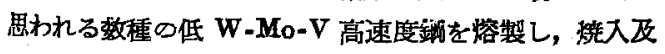

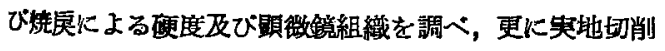
酎久力試験を行い, 此の種但 W-Mo-V 高速度塗の性 能を確めた。文従来のタングステン高速度釬及びモりフ テン高速度鍮との比䧶をむなした。

\section{II. 試料}

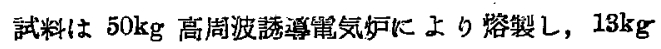

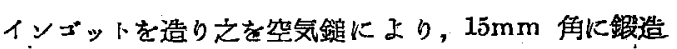
ᄂ，約 $900^{\circ} \mathrm{CK} 1$ 時間烧鏈した. 試料の化学成分を第

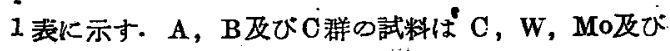
$\mathrm{V}$ 量種々異なる低 W-Mo- $\mathrm{V}$ 高速度蝴の代表的組成を 示し，D及びE試料は比较の為のモりブデン高速度鎙及 びタングステン高速度題を示す.

\section{III. 熱虑理の影很}

先ず本多式熱能脹計を用い，各試料の变態点を測定し た. その結果を第 2 表に示す。，但し最高加熱温度を 950 ${ }^{\circ} \mathrm{C}$ とした， C, Cr, V 活定の場合，且つW と $\mathrm{Mo}$ の和が活ほ一定のときWに対する、Mo 量が増す程加警

* 日立紫作所安來工場，工學博上

** 日立綮作所安來工場 


\begin{tabular}{|c|c|c|c|c|c|}
\hline 試料 & C & $\mathrm{Or}$ & $\mathbf{w}$ & Mo & $\mathrm{V}$ \\
\hline $\begin{array}{l}\text { A } 1 \\
\text { A } 2 \\
\text { A } 3 \\
\text { A } 4 \\
\text { A } 5\end{array}$ & $\begin{array}{l}1 \cdot 20 \\
1 \cdot 20 \\
1 \cdot 18 \\
1 \cdot 34 \\
1 \cdot 42\end{array}$ & $\begin{array}{l}3 \cdot 77 \\
3 \cdot 77 \\
3 \cdot 82 \\
3 \cdot 83 \\
4 \cdot 05\end{array}$ & $\begin{array}{r}6 \cdot 29 \\
-5 \cdot 80 \\
4 \cdot 74 \\
7 \cdot 47 \\
6 \cdot 54\end{array}$ & $\begin{array}{l}2 \cdot 42 \\
\mathbf{3} \cdot 73 \\
4 \cdot 12 \\
2 \cdot 09 \\
2 \cdot 79\end{array}$ & $\begin{array}{l}1 \cdot 95 \\
1 \cdot 95 \\
2 \cdot 05 \\
1 \cdot 70 \\
1 \cdot 90\end{array}$ \\
\hline $\begin{array}{ll}\text { B } & 1 \\
\text { B } & 5 \\
\text { B } & 8 \\
\text { B } & 4 \\
\text { B } & 5 \\
\text { B } & 6\end{array}$ & $\begin{array}{l}0.92 \\
0.98 \\
1.02 \\
0.96 \\
1.00 \\
0.98\end{array}$ & $\begin{array}{l}4 \cdot 13 \\
4 \cdot 06 \\
3 \cdot 69 \\
4 \cdot 11 \\
3 \cdot 98 \\
4 \cdot 09\end{array}$ & $\begin{array}{l}5 \cdot 67 \\
5 \cdot 96 \\
5 \cdot 72 \\
4 \cdot 05 \\
5 \cdot 63 \\
7 \cdot 61\end{array}$ & $\begin{array}{c}\text { tr. } \\
\mathbf{2} \cdot 69 \\
2 \cdot 79 \\
\mathbf{g} \cdot 55 \\
\mathbf{3} \cdot 26 \\
2 \cdot 02\end{array}$ & $\begin{array}{l}2 \cdot 40 \\
2 \cdot 40 \\
2 \cdot 85 \\
2 \cdot 35 \\
2 \cdot 01 \\
1 \cdot 65\end{array}$ \\
\hline $\begin{array}{ll}\text { C } & 1 \\
\text { C } & 2 \\
\text { C } & 3\end{array}$ & $\begin{array}{l}0 \cdot 88 \\
0.72 \\
0 \cdot 85\end{array}$ & $\begin{array}{l}4 \cdot 18 \\
\mathbf{3} \cdot 91 \\
\mathbf{3} \cdot 96\end{array}$ & $\begin{array}{l}7 \cdot 35 \\
5 \cdot 12 \\
3 \cdot 91\end{array}$ & $\begin{array}{l}2 \cdot 13 \\
2 \cdot 88 \\
4 \cdot 05\end{array}$ & $\begin{array}{l}2 \cdot 20 \\
2 \cdot 55 \\
1 \cdot 90\end{array}$ \\
\hline D 1 & $0 \cdot 76$ & $3 \cdot 62$ & 1.56 & $6 \cdot 25$ & $1 \cdot 63$ \\
\hline $\begin{array}{l}\text { E } 1 \\
\text { E } 2\end{array}$ & $\begin{array}{l}0.85 \\
0.84\end{array}$ & $\begin{array}{l}3 \cdot 96 \\
4 \cdot 06\end{array}$ & $\begin{array}{l}11 \cdot 33 \\
10 \cdot 88\end{array}$ & $\begin{array}{c}\text { tr. } \\
0 \cdot 18\end{array}$ & $\begin{array}{l}1 \cdot 58 \\
2 \cdot 30\end{array}$ \\
\hline
\end{tabular}

いては何れも 1150〜1200ㅇ で烧入による最高硬度を 示す. $1250^{\circ} \mathrm{C}$. 红温度を上界する捁と硬度を低下する は残留オーステナイトを增す為である。

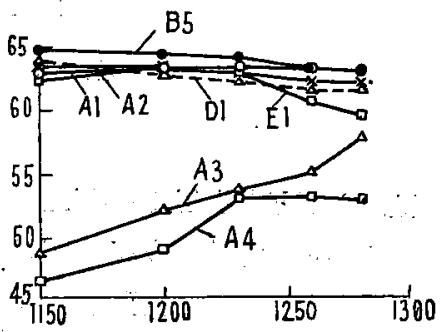

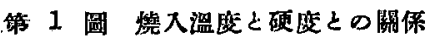

次に第 2 図一第 8 园は各試料の烧入温度による曄庆硬 䬺曲線を示す，何れる烧入温度を上年する任ど焼㞔によ る最高硬度は高い，焼戻による最高硬度を示す温度は試 料によつて異なり $550 \sim 575^{\circ} \mathrm{O}$ の間存する. 尚O量高 いA 4 及び A 5 試料は烧大硬度は低いが焼屈硬化度は 大でめる.而してこの種高 $\mathrm{C}$ の場合は前記研究に示す如 くV量を 3〜4\% に增す必要があり，V量低いときは組 瀻はかなり粗大化し脆性を増す。

\begin{tabular}{|c|c|c|c|c|c|c|}
\hline \multirow{3}{*}{ 弑料 } & \multicolumn{2}{|c|}{ 加熱学態 ${ }^{\circ} \mathrm{C}$} & \multicolumn{3}{|c|}{ 冾却紗態 } & ${ }^{\circ} \mathrm{O}$ \\
\hline & & & 烧 & 冾 & 空 & 冾 \\
\hline & 開始 & 終了 & 開始 & 終了 & 開始 & 終了 \\
\hline $\begin{array}{l}\text { A } 1 \\
\text { A } 2 \\
\text { A } 3 \\
\text { A } 4 \\
\text { A } 5\end{array}$ & $\begin{array}{l}835 \\
818 \\
806 \\
804 \\
801\end{array}$ & $\begin{array}{l}856 \\
845 \\
826 \\
826 \\
830\end{array}$ & $\begin{array}{l}756 \\
746 \\
748 \\
745 \\
736\end{array}$ & $\begin{array}{l}700 \\
716 \\
721 \\
698\end{array}$ & $\begin{array}{l}225 \\
150 \\
115 \\
119 \\
125\end{array}$ & $\begin{array}{l}- \\
- \\
-\end{array}$ \\
\hline $\begin{array}{l}\text { B } 1 \\
\text { B } 2 \\
\text { B } ~ \\
\text { B } 4 \\
\text { B } 5 \\
\text { B } 6\end{array}$ & $\begin{array}{l}845 \\
850 \\
856 \\
844 \\
810 \\
792\end{array}$ & $\begin{array}{l}874 \\
880 \\
885 \\
873 \\
833 \\
818\end{array}$ & $\begin{array}{l}746 \\
763 \\
774 \\
740 \\
726 \\
-\end{array}$ & $\begin{array}{r}692 \\
716 \\
720 \\
710 \\
690 \\
-\end{array}$ & $\begin{array}{l}258 \\
250 \\
258 \\
231 \\
156 \\
160\end{array}$ & $\begin{array}{l}150 \\
150 \\
155 \\
120 \\
- \\
-\end{array}$ \\
\hline $\begin{array}{l}01 \\
\text { C } 2 \\
\mathbf{O}^{2}\end{array}$ & $\begin{array}{l}835 \\
845 \\
805\end{array}$ & \begin{tabular}{|l}
853 \\
890 \\
835
\end{tabular} & $\begin{array}{l}715 \\
814 \\
738\end{array}$ & $\begin{array}{l}665 \\
729 \\
177\end{array}$ & $\begin{array}{l}205 \\
332 \\
124\end{array}$ & $\begin{array}{l}150 \\
247 \\
-\end{array}$ \\
\hline $\mathrm{D} 1$ & 824 & 848 & 745 & 700 & 294 & - \\
\hline $\begin{array}{l}\mathrm{E} 1 \\
\mathrm{E} ?\end{array}$ & $\begin{array}{l}822 \\
850\end{array}$ & $\begin{array}{l}850 \\
886\end{array}$ & $\begin{array}{l}749 \\
789\end{array}$ & $\begin{array}{l}726 \\
732\end{array}$ & $\begin{array}{l}175 \\
315\end{array}$ & $\overline{248}$ \\
\hline
\end{tabular}

の際の变態点は低下する. 一方收冾の際の变態点は余り 大差ない.而して空冷の際の Ar' 点は Mo 量を増す

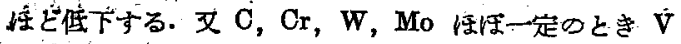

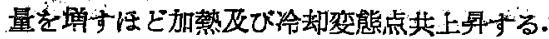

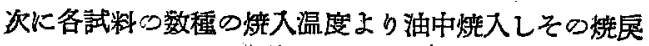
温度と硬度との関低を求めた。第 1 园は代表的各試料の 焼入温度と硬度との関俰を示ず. A 3 及びA4 試畘を除

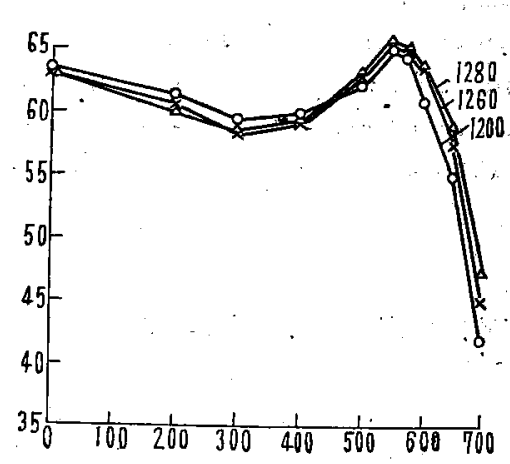

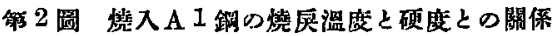

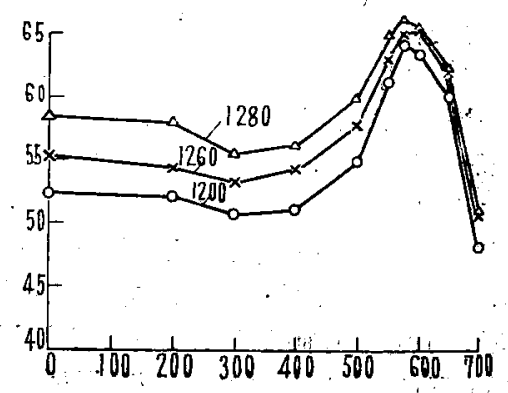

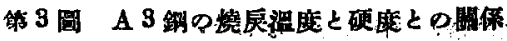




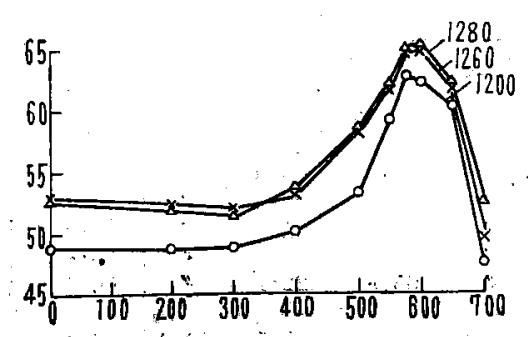

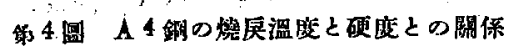

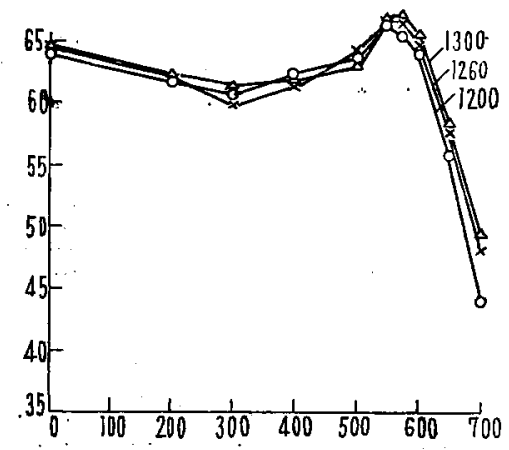

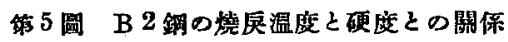

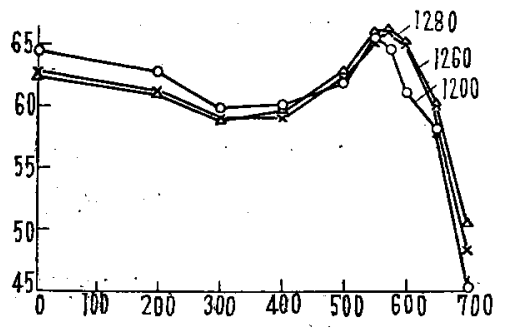

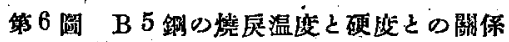

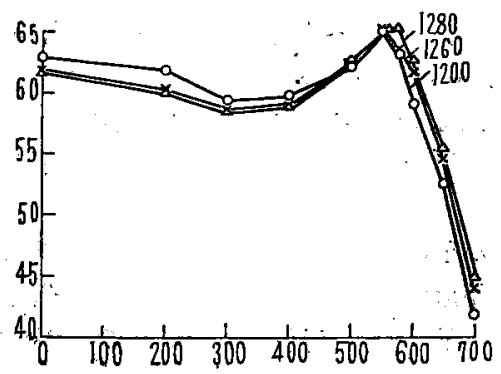

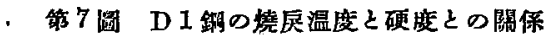

佮此処火注目すべきは此の種低 W-Mo-V 高速度鎯

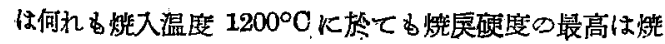
入硬度よりかなり高いといらことである.

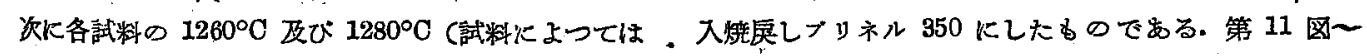
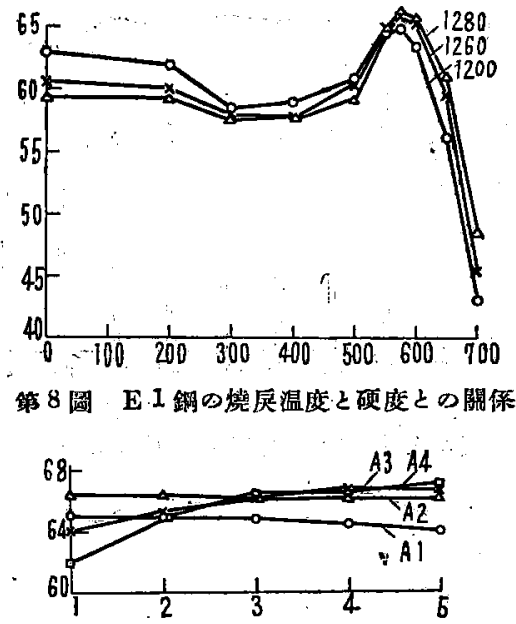

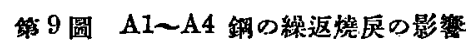
(嗉入温底 $1260^{\circ} \mathrm{C}$ )

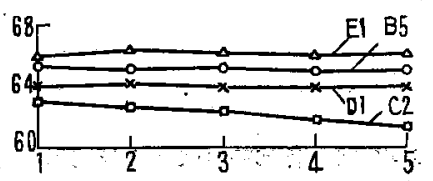

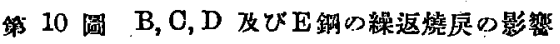
(烧入溫度 $1260^{\circ} 0$ )

$1300^{\circ} \mathrm{C}$ つより油中焼入したるのを $575^{\circ} \mathrm{O}$.に絽返し 5 回 焼戻を行つた場合の硬度の変化を調べた. その結果を第

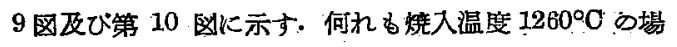
合を示す. 各試料によつて多少異なり A1 飞び A2 試 料比ては 2 回までは殆んど变りなく 3 回为上繰返すと 减少する.A3 及び A 4 試料比て於て 3〜4 回で最高 硬度を示す.A4 の場合は 5 回です堎增加の傾向を示 す. W $5 \cdot 68 \%$, Mo. 3.26\%, V 2.01\% の B 5 試料 ははほ 2 回で最高硬度を示する1回焙戻と余り变りな い. 低タングステン高速度銅及びモリブデン高速度銅と 余り变りない，O量低い低 W-Mo-V 高速度鋼 $\mathrm{O} 2$ \% 場合は焼戻を繰返えす汪と潮次硬度を低下する。

\section{IV. 切削耐久試驗}

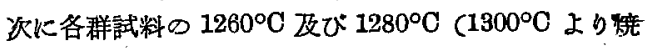
入したものるむる.つより烧入したものを $575^{\circ} \mathrm{CK} 2$ 回燎 戻を繰返えし，切削試匰を行つた. 被切削材料及び切削、 試駼方法之の他は前述と同様で岕る. 即方被切削材料は C $0.38 \%$, Mn $1.02 \%$, Or 0.98\% の Mn-Cr 鎙の絖 


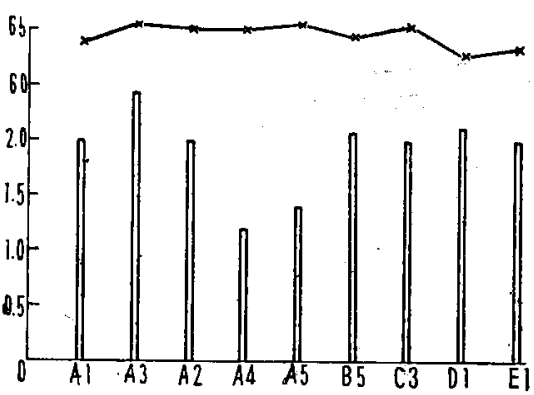

场 11 圆各試料の硬度と切别耐久力 （烧入 $1260^{\circ} \mathrm{C}$, 㮦廆 $575^{\circ} \mathrm{C} 2$ 回了

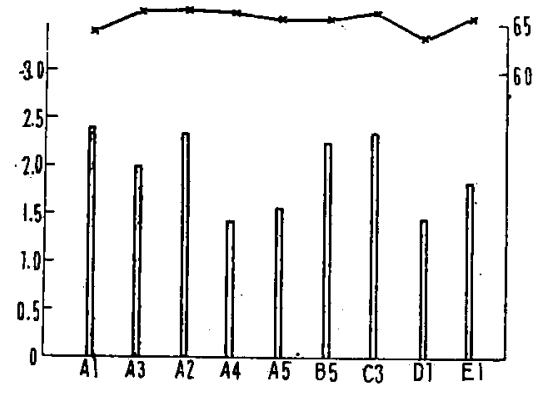

第 12 圆 各試料心硬度々切舦耐久力

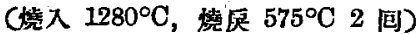

第 12 区はその結果の一例を示す・烧入温度 $1260^{\circ} \mathrm{C}$ ○ 場合は $\mathrm{W}$ 約 $5 \%, \mathrm{Mo}$ 約 $4 \%, \mathrm{~V}$ 約 $2 \%$ ○ A 3 試 料が耐久力が最す高いA A A2, B 5, C3 は余り大 差なく，及モリブデン高速度鎾及び低タングステン高速

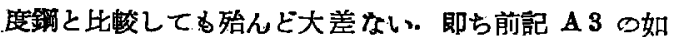
きは従来の高タングステン (18-4-1) 及び低タングステ ン高速度鎆よりまさる．高宸素一低.W-Mo-V 高速度 鋸 (V量低い) A 4 及び A 5 は何れるかなり劣る. 焼 入温度 $1280^{\circ} \mathrm{C}$ の場合はW約 $6 \%, \mathrm{Mo}$ 約 $2.5 \%, \mathrm{~V}$ 約 $2 \%$ D 1, W 約 6\%, Mo 約 4\%, V 約 $2 \%$ A2, $\mathrm{W}$ 約 $4 \%, \mathrm{Mo}$ 約 $4 \%, \mathrm{~V}$ 約 $2 \%$ の $\mathrm{C}$ 何れ子最。

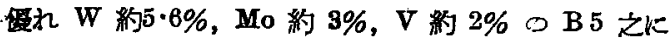

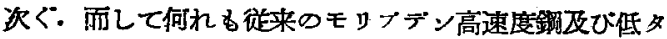
ングンテン高速度鎉にまさる.

次に第 3 表は同様 $1260^{\circ} \mathrm{C}$ 及び $1300^{\circ} \mathrm{C}$ 烧入試料の 切削耐久力の比较を示寸，これ加らる明らかに約 $6 \%$

\begin{tabular}{|c|c|c|c|c|c|c|}
\hline 試料 & $\begin{array}{l}\text { 炇入 } \\
\text { 温䵇 } \\
{ }^{\circ} \mathrm{C}\end{array}$ & 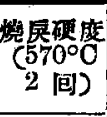 & $\begin{array}{l}\text { 切 } \text { h }^{*} \\
\text { 耐久力 } \\
V_{20} \\
\mathrm{~m} / \mathrm{min} \\
\end{array}$ & $\begin{array}{l}\text { 燒入 } \\
\text { 盢度 } \\
{ }^{\circ} \mathrm{C}\end{array}$ & 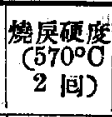 & $\begin{array}{l}\text { 都 } \\
\text { 耐火力 } \\
V_{20} \\
\mathrm{~m} / \mathrm{min}\end{array}$ \\
\hline $\begin{array}{lll}\text { B } & 1 \\
\text { B } & 2 \\
\text { B } & 3 \\
\text { B } & 4 \\
\text { B } & 5\end{array}$ & $\begin{array}{c}1260 \\
" \prime \\
" \prime \\
" \prime\end{array}$ & $\begin{array}{l}66 \cdot 0 \\
65 \cdot 8 \\
65 \cdot 9 \\
65 \cdot 5 \\
65.8\end{array}$ & $\begin{array}{l}20 \cdot 9 \\
22 \cdot 2 \\
21 \cdot 6 \\
20 \cdot 6 \\
22 \cdot 1\end{array}$ & $\begin{array}{c}1300 \\
"\end{array}$ & $\begin{array}{l}65 \cdot 8 \\
68 \cdot 2 \\
66 \cdot 2 \\
65 \cdot 8 \\
66 \cdot 2\end{array}$ & $\begin{array}{l}23 \cdot 1 \\
23 \cdot 8 \\
22 \cdot 5 \\
23 \cdot 5 \\
22 \cdot 8\end{array}$ \\
\hline $\begin{array}{ll}\text { C } & 1 \\
\text { C } & 2\end{array}$ & 1260 & $\begin{array}{l}65 \cdot 8 \\
64 \cdot 2\end{array}$ & $\begin{array}{l}21 \cdot 5 \\
20 \cdot 4\end{array}$ & 1200 & $\begin{array}{l}66.4 \\
64.4\end{array}$ & $\begin{array}{l}22 \cdot 5 \\
22 \cdot 1\end{array}$ \\
\hline E 2 & 1260 & $64 \cdot 2$ & $20 \cdot 0$ & 1300 & $66 \cdot 0$ & $22 \cdot 8$ \\
\hline
\end{tabular}

Mo 約 $2 \cdot 7 \%, \mathrm{~V} 2.5 \%$ の , B2 試料, W約 $4 \%$, Mo $3.5 \%, V$ 約 2.5\% の B 4 試料は熱边理方法によ つてはかなりすぐれた性能を示すことが判る.

\section{V. 結 論}

上述の研究結果を要約すると次の通りである。

(1) 数種の低 $\mathrm{W}-\mathrm{Mo}-\mathrm{V}$ 高速度鏰の熱処理と切削䎟 久力との関係を調ヘ，往来のモリブデン高速度鎯及び低 タングステン高速庭鎙との比較をなした。

(2) 焼入及び焼㞔による硬度の变化並びに繰返焼㞔の 影睤を確めた。

(3) 各種組成の最も適当々熱処㻎温度を確むた。

(4) 切削耐久力は組成によつて異なる。焼入湿度高い 方がー一般に切削耐久力は高い。

（5）これ等の研究の結果加最適当と思われる組成

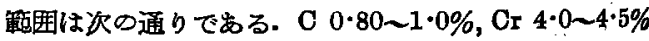
W 4.0 5.0\%, Mo 3.0 4.0\%, V 2.0 $2 \cdot 5 \%, 01$. $0 \sim 1 \cdot 2 \%$, Cr $4 \cdot 0 \sim 4 \cdot 5 \%, W 5 \cdot 0 \sim 6 \cdot 0 \%$, Mo $2 \cdot 5 \sim$ $3^{\prime} \cdot 5 \%, V \cdot 2 \cdot 5 \sim 3 \cdot 0 \%$.

本研究を逐行するに当り熱心に箺験に彷事された塩谷 義雄君の学を多とする.（昭和 29 年 4 月寄稿)

$$
\text { 文 献 }
$$

1) 小柴: 鐵と鎆, 33 (1947), No. 1 3, p. 22

2) 小柴: 较と䤡, 32 (1946), No. 7 9, p. 9

3）小柴：日本全席學會誌，16 (1952); No.9, p. 511 